\title{
NUMERICAL STUDY OF THE INFLUENCE OF GEOMETRIC PARAMETERS ON THE AVALIABLE POWER IN A SOLAR CHIMNEY
}

\author{
R. S. Vieira ${ }^{\mathrm{a}}$, \\ C. Garcia ${ }^{a}$, \\ I. C. A. Junior ${ }^{b}$, \\ J. A. Souza ${ }^{a}$, \\ L. A. O. Rochac, \\ L. A. Isoldi ${ }^{a}$, \\ and E. D. dos Santos ${ }^{\mathrm{a}}$ \\ ${ }^{a}$ Universidade Federal do Rio Grande \\ Escola de Engenharia \\ Av. Itália, km 8, CEP 96.201-090, \\ Rio Grande, RS, Brasil \\ rodrigospotorno@yahoo.com.br \\ bInstituto Federal de Educação, Ciência e \\ Tecnologia do Rio Grande do Sul, IFRS \\ Rua Alfredo Huch, 475, CEP 96201-090, \\ Rio Grande, RS, Brasil \\ 'Departamento de Engenharia Mecânica, \\ Universidade Federal do Rio Grande do Sul \\ Rua Sarmento Leite, 425, CEP 90050-170, \\ Porto Alegre, RS, Brasil \\ Received: March 04, 2015 \\ Revised: April 06, 2015 \\ Accepted: May 07, 2015
}

\section{ABSTRACT}

In the presented work, it is made a numerical study about the main physical principle of a solar chimney (SCPP - Solar Chimney Power Plant) and the influence of some geometric parameters on the available power in the SCPP. The main objectives are to test the applicability of the studied numerical model in future studies of SCPP geometric optimization and to test the action of the collector inlet height $\left(H_{1}\right)$ and the chimney outlet diameter $\left(D_{2}\right)$ on the available power of the device. For that it is considered an incompressible, turbulent, steady flow with mixed convective heat transfer in a two-dimensional and axisymmetric domain, similar to the one found in a solar chimney. The conservation equations of mass, momentum and energy are numerically solved using the finite volume method, more specifically with the FLUENT ${ }^{\circledR}$ software. The classical turbulence modeling (RANS) was used for the turbulence approach with standard model $k-\varepsilon$. The other geometric parameters: collector radius $(R)$ and the inlet and outlet of the turbine section, $R_{1}$ and $R_{2}$, are also constant. The verification results indicated a good agreement with those presented in the literature, even using a simplified domain. It was also observed that the $H_{1}$ parameter is almost insensitive in the solar chimney performance, whereas the $D_{2}$ variable presented great influence in the available power. The best performance was attained for an intermediate value of $D_{2}, D_{2}=0.44 \mathrm{~m}$. For this value, the available power was almost $72 \%$ and $19 \%$ higher from those obtained in the inferior and superior extremes of the studied $D_{2}$ variable, $D_{2}$ $=0.22 \mathrm{~m}$ and $0.88 \mathrm{~m}$, respectively. It was also observed that there is a very good possibility of optimization of the chimney geometry in future studies.

Keywords: solar chimney, numerical study, available power, geometric parameters

\section{NOMENCLATURE}

A Area, $\mathrm{m}^{2}$

D Diameter, $\mathrm{m}$

g Gravity, $\mathrm{m} / \mathrm{s}^{2}$

$H \quad$ Height, $\mathrm{m}$

$k \quad$ Kinetic energy, J

$p \quad$ Pressure, $\mathrm{Pa}$

$P_{a v} \quad$ Available power, $\mathrm{W}$

$R \quad$ Radius, $\mathrm{m}$

SCPP Solar Chimney Power Plant

$T$ Temperature, $\mathrm{K}$

$t \quad$ Time domain, $\mathrm{s}$

$u \quad$ Velocity in $x$ direction, $\mathrm{m} / \mathrm{s}$

$v \quad$ Velocity in $y$ direction, $\mathrm{m} / \mathrm{s}$

$V \quad$ Air flow velocity, $\mathrm{m} / \mathrm{s}$

() Time-averaged variables

\section{Greek symbols}

$\alpha \quad$ Thermal diffusivity, $\mathrm{m}^{2} / \mathrm{s}$

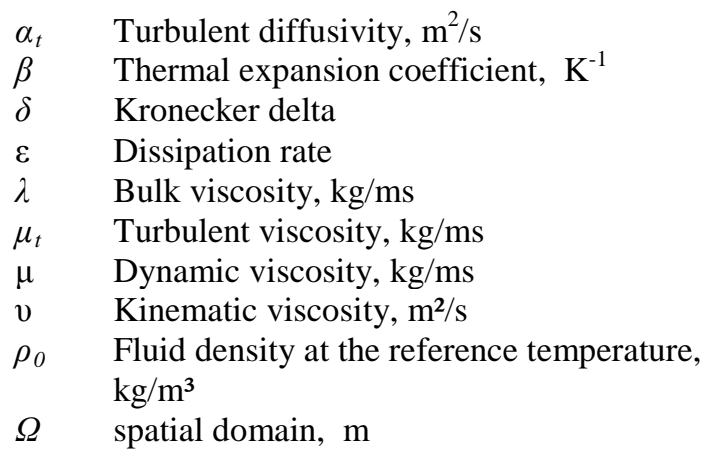

\section{INTRODUCTION}

The increase of oil prices and energy demand combined with recent environmental restrictions have quickly raised the global demand for renewable energy sources. The solar energy is one of the most promising solutions, especially considering its technology, improvements and fast development. According to $\mathrm{Li}$ et al. (2014), solar energy is free 
from carbon emission, inexhaustible, sustainable, free from costs (in its basic form) and practically unlimited. Beyond that, it has an enormous potential, which could supply the world energy demand. Therefore, recently, with the decrease of fossil energetic resources and the increased effects of global warming, many countries have provided financial incentives for the development of solar power plants, including not returnable subsidy, longterm loans with reduced taxes and others. One of the alternatives proposed in the literature supply those demands is the solar chimney power plant (SCPP). The SCPP is a proposal of a type of renewable power plant, which turns solar energy into electricity.

The Solar Chimney power plant is composed by three essential parts - the collector, the chimney and the turbines. The chimney is a long cylindrical structure usually positioned in the center of a greenhouse collector, which is made of transparent glass or plastic film (Patel et al., 2014). According to Jones (2011), the physical principle of operation of the solar chimney consists in the heating of an air layer, which is hold inside the collector. The heating is carried out by the incidence of solar energy in this film, where some of the radiant energy is going to be transmitted through the collector to the air between the film and the ground. The transmitted solar energy hits the surface of the ground and the latter absorb part of it, while the other part is reflected back to the collector. With modified wavelength, upon the incidence in the ground, the radiant energy suffers multiple reflections between the ground and the collector film, resulting in an increase of the absorbed energy by the ground. Once the ground is warm, the air inside the collector also warms up and tend to move by natural convection to the chimney region, expanding though a turbine, which is located between the collector and the chimney (which has its outlet in an atmospheric pressure region). It is worth notice that, when the warm air moves up to the chimney, a depression region is generated in the collector periphery which causes the external air mass suction that exchanges heat with the ground and the collector, intensifying the thermal Exchange in the collector region and increases the movement quantity of the air that expands through the turbine. This kinetic energy of the air turns the turbine blades, which move the energy generators. That way, one of the main objectives in solar chimney projects is to increase the movement quantity in the turbine region.

The energy technology of the solar chimney is well seen as one of the methods that can utilize solar energy in large scale. The solar chimney has no adverse effect on the environment, do not need water for refrigeration and has a low maintenance cost, unlike what is reality in other solar energy devices that require high financial cost technology (which makes it unfeasible in large scale). Those advantages makes the SCPP a promising technology for electricity generation in regions with abundant solar energy such as Brazil, for example (Li et al, 2014).

Some studies were performed in the area such, for instance, development of a mathematical model to prescribe the potency for the solar radiation variation, collector area and chimney height. The analytical results were compared with experimental results of a small-scale pilot plant yielding a good concordance with Zhou et al. (2007).

According to Dhahri and Omri (2013), the presented SCPP research in literature can be separated in four groups: (1) the concept and validation of working principle, (2) simulation of device performance and structural optimization, (3) estimative of power capacity and (4) technical and economic evaluation. The concept and working principle of the SCPP are validated mainly through experimental devices and analytical calculations, one of the most successful among the presented is the Manzanares plant, in Spain (Haaf et al., 1983). It is also presented in literature the development of mathematical model to stimulate the system performance (Pretorius and Kröger, 2006). Relative to numerical studies, some has been dedicated to understanding the behavior of velocity field, pressure and temperature in the SCPP and regarding the turbine performance (Xu et al, 2011). In the work of Patel et al. (2014), some parameters of the principal components of a SCPP were varied in order to maximize the useful available power in the turbine region. All of the geometries were evaluated numerically using the Computation Fluid Dynamics (CFD) software ANSYS-CFX. In this study, once a three-dimensional domain was considered, it was possible to perform 12 simulations to attain a tendency of the effect of the collector height, collector outlet diameter and diameter of the chimney region on the available power in the turbine.

In the presented study will be evaluated the use of a simplified numerical model, similar to the one used to Patel et al. (2014), in a two-dimensional, axisymmetric domain in a incompressible, turbulent and permanent flow with heat transfer through mixed convection. The main advantage of using a simplified model is the possibility to minimize computational effort, allowing the achievement of a greater number of simulations. At all were attained 28 simulations allowing the evaluation of the collector height and chimney outlet diameter influence on the useful available power on the SCPP turbine. To attain this evaluation the time-averaged conservation equations of mass, momentum and energy were numerically solved with the Finite Volume Method (FVM) (Patankar, 1980; Versteeg and Malalasekera, 2007). More specifically, the FLUENT ${ }^{\circledR}$ (FLUENT, 2007) software is used. For the numerical approach of the turbulence is used the classical modeling (RANS Reynolds Averaged Navier-Stokes) which consists in the application of a time-averaged operator in the conservation equations (Wilcox, 2002). To solve the closing problem of the turbulence is used the two 
differential equations model $\mathrm{k}-\varepsilon$ (launder and Spalding, 1972).

\section{MATHEMATICAL AND NUMERICAL MODELING}

The time-averaged conservation equations of mass, momentum and energy for the solution of turbulent, incompressible flows with heat transfer by mixed convection are given by (Bejan, 2013):

$$
\begin{gathered}
\frac{\partial \overline{u_{i}}}{\partial x_{i}}=0 \\
\rho_{0}\left[\frac{\partial}{\partial t}\left(\overline{v_{i}}\right)+\frac{\partial}{\partial x_{j}}\left(\overline{v_{i} v_{j}}\right)\right]+\frac{\partial \bar{P}}{\partial x_{j}} \delta_{i j} \\
-\frac{\partial}{\partial x_{j}}\left\{\left(\mu+\mu_{t}\right)\left(\frac{\partial \overline{v_{i}}}{\partial x_{j}}+\frac{\partial \overline{v_{j}}}{\partial x_{i}}\right)\right\} \\
+\rho_{0} g_{i} \beta\left(\bar{T}-T_{0}\right)=0 \\
\frac{\partial \bar{T}}{\partial t}+\frac{\partial}{\partial x_{j}}\left(\overline{v_{j} T}\right)-\frac{\partial}{\partial x_{j}}\left\{\left(\alpha+\alpha_{t}\right) \frac{\partial \bar{T}}{\partial x_{j}}\right\}=0
\end{gathered}
$$

where $\left(^{-}\right)$represents the time average operator, $\rho_{0}$ is the fluid density at reference temperature $\left(\mathrm{kg} / \mathrm{m}^{3}\right) ; \beta$ is the coefficient of thermal expansion $\left(\mathrm{K}^{-1}\right) ; \mu$ is the dynamic viscosity $(\mathrm{kg} / \mathrm{ms}) ; \lambda$ is the bulk viscosity $(\mathrm{kg} / \mathrm{ms}) ; v$ is the kinematic viscosity $\left(\mathrm{m}^{2} / \mathrm{s}\right) ; \alpha$ is the thermal diffusivity $\left(\mathrm{m}^{2} / \mathrm{s}\right) ; v_{i}$ is the velocity in the direction $i, i=1,2$ and $3(\mathrm{~m} / \mathrm{s})$; corresponds to the spatial coordinate $x_{i}, i=1,2$ and $3(\mathrm{~m}) ; P$ is the pressure $(\mathrm{N} / \mathrm{m})$; $T$ is the temperature $\left({ }^{\circ} \mathrm{C}\right.$ or $\left.\mathrm{K}\right) ; T_{0}$ is a reference temperature $\left({ }^{\circ} \mathrm{C}\right.$ or $\left.\mathrm{K}\right) ; g_{i}$ is the acceleration of gravity in the direction $i, i=1,2$ and 3 $\left(\mathrm{m} / \mathrm{s}^{2}\right) ; \delta_{i j}$ is the Kronecker delta; $\Omega$ is the spatial domain (m); $t$ is the time domain (s).

Turbulent viscosity $\left(\mu_{t}\right)$ and the turbulent diffusivity $\left(\alpha_{t}\right)$ are given by:

$$
\begin{gathered}
\mu_{t}=\rho C_{\mu} \frac{k^{2}}{\varepsilon} \\
\alpha_{t}=\frac{v_{t}}{\operatorname{Pr}_{t}}
\end{gathered}
$$

To estimate the $\mu_{\mathrm{t}}$ is necessary to obtain values of the turbulent kinetic energy $(k)$ and its dissipation rate $(\varepsilon)$ along the domain. For this, two additional equations are solved (Wilcox, 2002; Launder and Spalding, 1972) are given by:

$$
\frac{\partial k}{\partial t}+\bar{v}_{j} \frac{\partial k}{\partial x_{j}}
$$

$$
\begin{gathered}
=\tau_{i j} \frac{\partial \bar{v}_{i}}{\partial x_{j}}+\frac{\partial}{\partial x_{j}}\left[\left(v+\frac{v_{t}}{\sigma_{k}}\right) \frac{\partial k}{\partial x_{j}}\right]-\varepsilon \\
\frac{\partial \varepsilon}{\partial t}+\bar{v}_{j} \frac{\partial \varepsilon}{\partial x_{j}}=\frac{\partial}{\partial x_{j}}\left[\left(v+\frac{v_{t}}{\sigma_{\varepsilon}}\right) \frac{\partial \varepsilon}{\partial x_{j}}\right] \\
+C_{\varepsilon 1} \frac{\varepsilon}{k} \tau_{i j} \frac{\partial \bar{v}_{i}}{\partial x_{j}}-C_{\varepsilon 2} \frac{\varepsilon^{2}}{k}
\end{gathered}
$$

The constants employed to solve the additional transport equations, Eqs (4) - (7) are shown in Tab. 1.

Table 1. Constants used in the $k-\varepsilon$ model, Eqs. (4-7).

\begin{tabular}{cccccc}
\hline$C_{\mu}$ & $C_{\varepsilon 1}$ & $C_{\varepsilon 2}$ & $\sigma_{k}$ & $\sigma_{\varepsilon}$ & $\operatorname{Pr}_{t}$ \\
\hline 0.09 & 1.44 & 1.92 & 1.0 & 1.3 & 1.0 \\
\hline
\end{tabular}

The conservation equations that model the problem, Eqs. (1) - (3), as well as the differential equations of the turbulence model $k-\varepsilon$ are solved using the finite volume method (FVM), specifically using the software FLUENT (FLUENT, 2007). The solver is pressure based and all the simulations use the advection scheme $2^{\text {nd }}$ Order Upwind and the SIMPLE method for the pressure velocity coupling. More details about the FVM can be found in Patankar (1980) and Versteeg and Malalasekera (2007).

The numerical simulations were attained in a computer equipped with 6 processors AMD FX6300 with $3.5 \mathrm{GHz}$ clock and an installed $4 \mathrm{~GB}$ RAM memory. The processing time for the simulations was approximately $1.5 \times 10^{2} \mathrm{~s}$. The simulations were considered converged when the residuals for mass, velocity, energy and for the equations of the turbulence model between two consecutive iterations were smaller than $10^{-6}, 10^{-6}, 10^{-8}$ e $10^{-6}$, respectively. Beyond that, sub-relaxation factors of 0.7 were imposed in the conservation equations. In all of the simulations were used 5000 iterations and one test of mesh independence was carried out to define the best mesh to be used in this kind of problem. The study above quoted is going to be presented after the problem definition (next section).

\section{PROBLEM DESCRIPTION}

The problem consists in the evaluation of some geometric parameters variation over the flow in a solar chimney and over its available power. In the presented work, the chimney outlet diameter $\left(D_{2}\right)$ and the collector inlet height $\left(H_{1}\right)$ are evaluated (Fig. 1). In all the cases, the SCPP height, the collector radius, the inlet and outlet radius of the turbine section are steady, $H=10.0 \mathrm{~m}$ and $R=4.0 \mathrm{~m}, R_{1}=0.5 \mathrm{~m}$ and $R_{2}$ $=0.125 \mathrm{~m}$, respectively. Concerning with the physical conditions of the problem, were imposed here the same considerations used by Patel et al. (2014), except for the computational domain, that 
was considered axisymmetric. The work fluid is air, the latter being considered an ideal gas. The natural convection was considered by the Boussinesq hypothesis. The acceleration of the gravitational field acts in the negative way of the $y$ direction, as shown in Fig. 1. The reference pressure is atmospheric ( $p_{\text {ref }}$ $=1.0 \mathrm{~atm})$. For the other boundary conditions, $\mathrm{a}$ constant pressure $\left(p_{\text {ref }}=1.0 \mathrm{~atm}\right)$ and temperature $\left(T_{1}\right.$ $=303 \mathrm{k}$ ) is imposed in the collector inlet (surface $S_{1}$ ), in order to simulate the region conditions. The same pressure and temperature are imposed in the chimney outlet (surface $\mathrm{S}_{2}$ ), i.e., $p_{2}=1.0 \mathrm{~atm}$ e $T_{2}=303 \mathrm{~K}$. To the ground (surface $S_{3}$ ) is given a condition of no sliding and impermeability. Besides that, a temperature of $T_{3}=323 \mathrm{~K}$ is considered, simulating the soil warming effect by the energy absorbed in the collector. The remaining surfaces in the computational domain have no sliding and impermeability condition and they are thermally isolated (adiabatic).

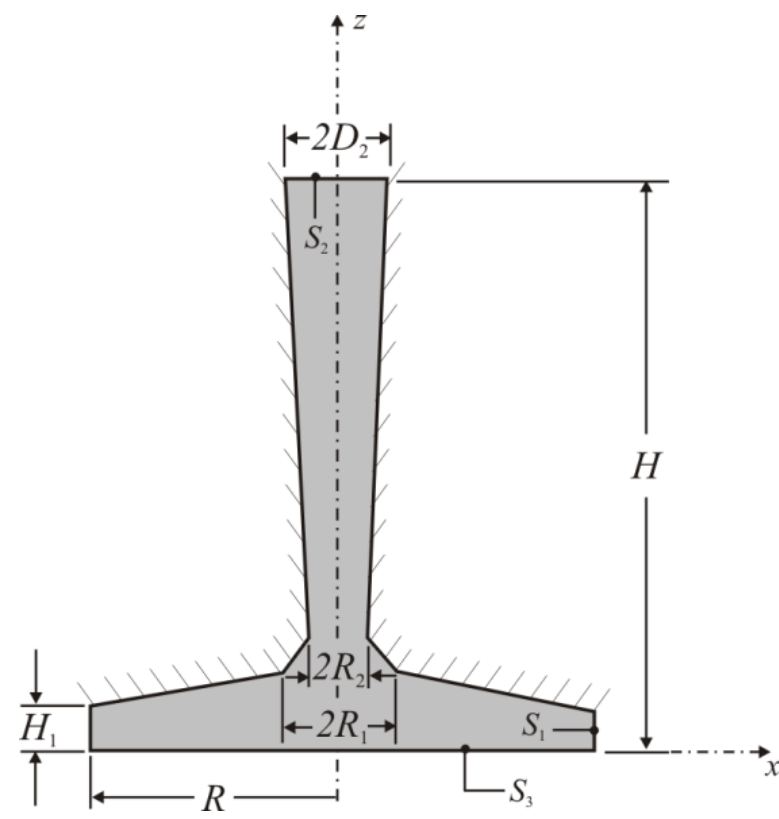

Figure 1. Computation domain used in the simulation of the SCPP.

The main goal of the presented work is to maximize the available power in the solar chimney by, as well, evaluate the effect of the parameters $D_{2}$ and $H_{1}$ on the device performance. The available power in the SCPP is given from the following expression:

$$
P_{a v}=0.5 \rho A V^{3}
$$

where $\rho$ is the air density $\left(\mathrm{kg} / \mathrm{m}^{3}\right), A$ is the transversal section of the SCPP in the turbine region $\left(\mathrm{m}^{2}\right)$ and $V$ is the spatial average velocity in the analyzed section $(\mathrm{m} / \mathrm{s})$.

Table 2 presents the studied values of $D_{2}$ and $H_{1}$ investigated here.
Table 2. Values of $D_{2}$ and $H_{1}$ investigated in the presented study.

\begin{tabular}{cccccc}
\hline Case & $\begin{array}{c}D_{2} \\
(\mathrm{~m})\end{array}$ & $\begin{array}{c}H_{1} \\
(\mathrm{~m})\end{array}$ & Case & $\begin{array}{c}D_{2} \\
(\mathrm{~m})\end{array}$ & $\begin{array}{c}H_{1} \\
(\mathrm{~m})\end{array}$ \\
\hline 1 & 0.22 & 0.05 & 15 & 0.66 & 0.05 \\
2 & 0.22 & 0.06 & 16 & 0.66 & 0.06 \\
3 & 0.22 & 0.07 & 17 & 0.66 & 0.07 \\
4 & 0.22 & 0.075 & 18 & 0.66 & 0.075 \\
5 & 0.22 & 0.08 & 19 & 0.66 & 0.08 \\
6 & 0.22 & 0.09 & 20 & 0.66 & 0.09 \\
7 & 0.22 & 0.1 & 21 & 0.66 & 0.1 \\
8 & 0.44 & 0.05 & 22 & 0.88 & 0.05 \\
9 & 0.44 & 0.06 & 23 & 0.88 & 0.06 \\
10 & 0.44 & 0.07 & 24 & 0.88 & 0.07 \\
11 & 0.44 & 0.075 & 25 & 0.88 & 0.075 \\
12 & 0.44 & 0.08 & 26 & 0.88 & 0.08 \\
13 & 0.44 & 0.09 & 27 & 0.88 & 0.09 \\
14 & 0.44 & 0.1 & 28 & 0.88 & 0.1 \\
\hline
\end{tabular}

\section{RESULTS AND DISCUSSION}

First, a mesh independence study of the computational domain used is carry out. In all cases the domain was subdivided in rectangular finite volumes and in the wall and turbine regions was used a further refinement of the mesh using a stretched mesh. The investigated mesh were divided in the following number of volumes: 500, 1100, 2120, $6540,17400,31670$. The velocity profile in the symmetry region of the domain attained with the different tested meshes are presented in Fig. 2. The results indicate that the mesh with 500 and 2120 volumes underestimate significantly the velocity field in the turbine outlet region, where the top velocities are attained. In addition, it can be observed that the obtained profiles with 25200 and 31500 volumes present an excellent concordance, with a variation inferior to $0.5 \%$. On that basis, it is considered an independent mesh with 25200 volumes and the former is going to be used in the remainder of the realized simulations in the presented work.

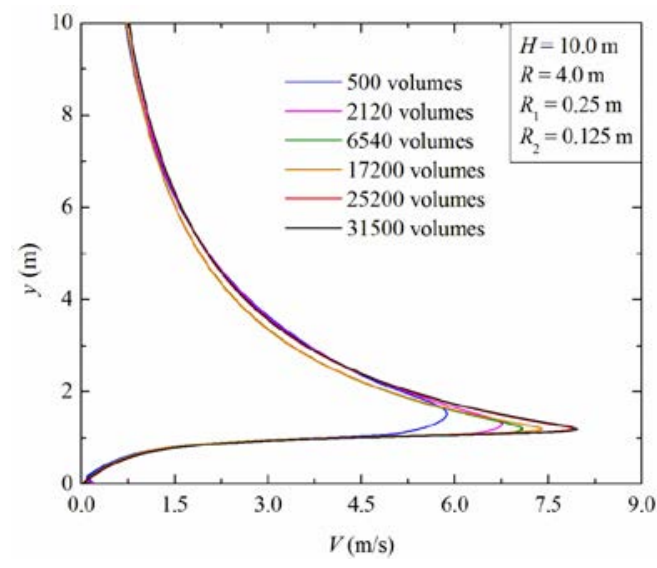

Figure 2. Mesh independence study used in the SCPP.

After the mesh independence study, a 
verification of the obtained results is realized with the presented numerical mode and those obtained by Patel et al. (2014). Figure 3 illustrates a comparison of the velocity field magnitude in the axis region of the SCPP obtained in the present work with the ones presented in the lecture. It can be observed that the results present an average deviation of about $5.0 \%$. The top velocity found in the present simulations is $v_{\max }=7.91 \mathrm{~m} / \mathrm{s}$ while in Patel et al. (2014) was attained a top velocity of $v_{\max , 1}=7.50 \mathrm{~m} / \mathrm{s}$. In the results of the lecture a fluctuation in the velocity profile is found in the chimney outlet region, with a slight reduction in $y=9.0 \mathrm{~m}$ that is not obtained in the simulations of the present work. The behavior found in the lecture is not foreseen once there is no force in the chimney central region that can reduce the profile only in that region. Despite the differences shown between the obtained results and those of Patel et al. (2014), it is possible to claim that the results are satisfactory well concordant, mostly in the turbine region where the adequate estimative is more important for the available power estimative in the SCPP. Therefore, the present model is going to be used to evaluate the effect of the variables $D_{2}$ and $H_{1}$ over the available power of the device.

Figure 4 shows the effect of the variable $\mathrm{H}_{1}$ over the available power in the SCPP for the following values of ${ }_{D 2}: D_{2}=0.22,0.44,0.66$ and 0.88 . Generally, the results show that the reason $H_{1}$ did not present great sensitivity on the available power $(P)$ for none of the investigated $D_{2}$ values. For example, for $D_{2}=0.22 \mathrm{~m}$, the best performance was attained for $H_{1}=0.05 \mathrm{~m}$, similarly to that observed in Patel et al. (2014), and conducted to a power of 7.91 W while for the worst performance (observed for $H_{1}$ $=0.07 \mathrm{~m}$ ) was attained a power of only $11.0 \%$ inferior. The results also show that the best geometries for all values of $H_{1}$ are attained for $D_{2}=$ $0.44 \mathrm{~m}$. In average, the available power $(P)$ for $D_{2}=$ $0.44 \mathrm{~m}$ was approximately $70.0 \%$ superior to those obtained for the worst value of $D_{2}=0.22 \mathrm{~m}$.

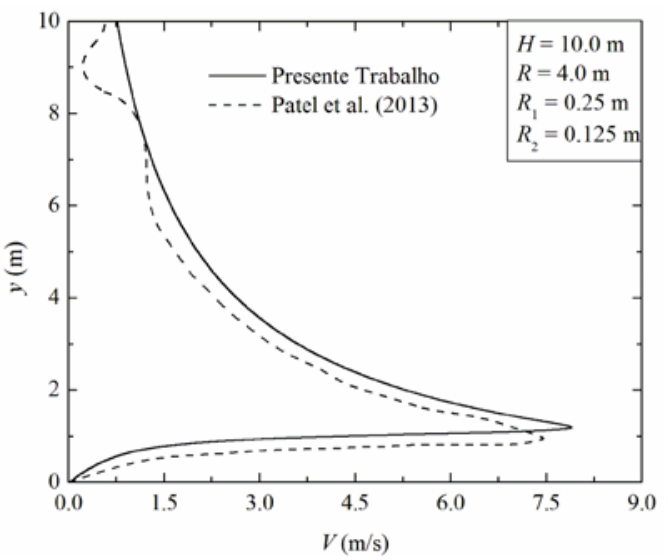

Figure 3. Comparison between the velocity profiles in the SCPP central region obtained in the present work and in Patel et al. (2014).

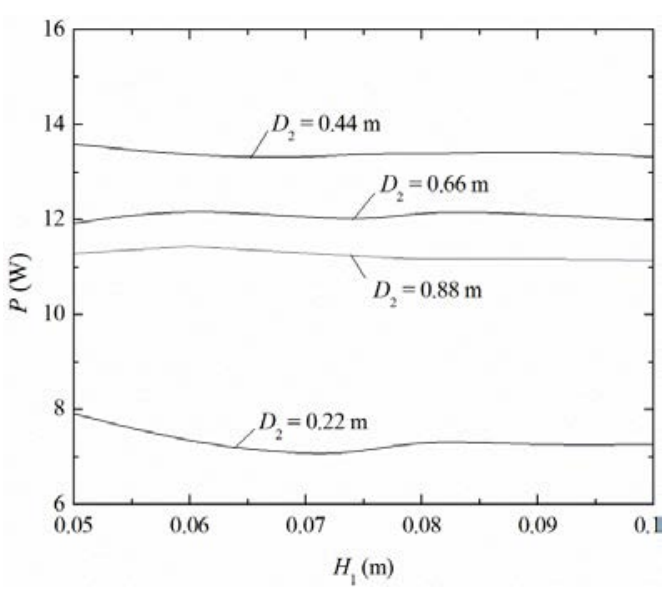

Figure 4. Effect of $H_{1}$ on the available power in the chimney for the several values of $D_{2}$.

The greater powers available obtained in Fig. 4 and their respective geometries are compiled and presented in Fig. 5. More precisely, it is evaluated the effect of variable $D_{2}$ on the maximum available power for the several values of $H_{1}$ studied $\left(P_{\mathrm{m}}\right)$ and the values of $H_{1}$ that lead to this better performance $\left(H_{1,0}\right)$. Unlike observed in Fig. 4, the results of Fig. 5 show that the variable $D_{2}$ has a strong influence over the SCPP performance. The best geometry was attained for the reason $D_{2}=0.44 \mathrm{~m}$ and conducted to a maximum available power of $P_{\mathrm{m}}=13.6 \mathrm{~W}$. This geometry presented a power with a performance of approximately $72 \%$ and $19 \%$ superior to the inferior $\left(D_{2}=0.22 \mathrm{~m}\right)$ and superior $\left(D_{2}=0.88 \mathrm{~m}\right)$ studied limits, respectively. In relation to the geometries of $H_{1}$ that lead to the best performance of the SCPP, there is not a great variation from lowest studied $D_{2}$ values $\left(D_{2}=0.22 \mathrm{~m}\right.$ and $\left.0.44 \mathrm{~m}\right)$ to the higher $\left(D_{2}=\right.$ $0.66 \mathrm{~m}$ and $0.88 \mathrm{~m}$ ), indicating that this variable can the maintained steady for the fixed geometry values in the present work $\left(H=10.0 \mathrm{~m}, R=5.0 \mathrm{~m}, R_{1}=0.5\right.$ $\mathrm{m}$ and $\left.R_{2}=0.125 \mathrm{~m}\right)$.

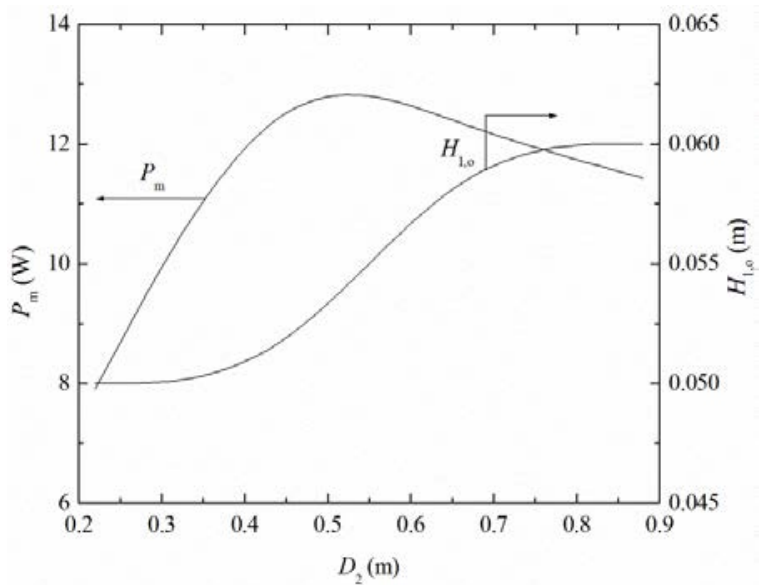

Figure 5. Effect of $D_{2}$ on the maximum power $\left(P_{\mathrm{m}}\right)$ and its respectively geometries for $H_{1}\left(H_{1,0}\right)$. 
The velocity fields for the best geometry shapes obtained in Fig. 5 are presented in Fig 6. Figure 8 (a c) shows the velocity fields for the geometries with $D_{2}=0.22 \mathrm{~m}, D_{2}=0.44 \mathrm{~m}$ and $D_{2}=0.88 \mathrm{~m}$, respectively. For $D_{2}=0.22 \mathrm{~m}$ can be noticed that there is a great restriction to flow because of the chimney funneling, resulting in a minor velocity field magnitude in the chimney region. For the upper extreme of $D_{2}\left(D_{2}=0.88 \mathrm{~m}\right)$ the velocity field magnitude grows in comparison with $D_{2}=0.22 \mathrm{~m}$, but the velocity field ends up being distributed in a not homogeneous way and with low intensity in the chimney outlet region, hampering the chimney drawing. In the case $D_{2}=0.44 \mathrm{~m}$ the distribution of the velocity field is more homogeneous throughout the domain, resulting in lesser flow restriction. Hence, there is obtained a greater magnitude between the compared geometries in the turbine region.

\section{CONCLUSIONS}

The present work carried out a numerical study to investigate the working principle of a SCPP. The main goals here presented were evaluate the applicability of the numerical model in forthcoming theoretical recommendations of the SCPP geometry on the available power of the device. All the cases considered a compressible, turbulent, steady flow with heat transfer through mixed convection in an axisymmetric two-dimensional domain. The equations of mass conservation, movement quantity and energy are numerically solved using the finite volume method, most precisely with the software FLUENT $^{\circledR} \quad$ (FLUENT, 2007; Patankar, 1980; Versteeg and Malalasekera, 2007). For the turbulence approach it is used the turbulence classic modelling (RANS) with model $k-\varepsilon$ (Launder and Spalding, 1972).

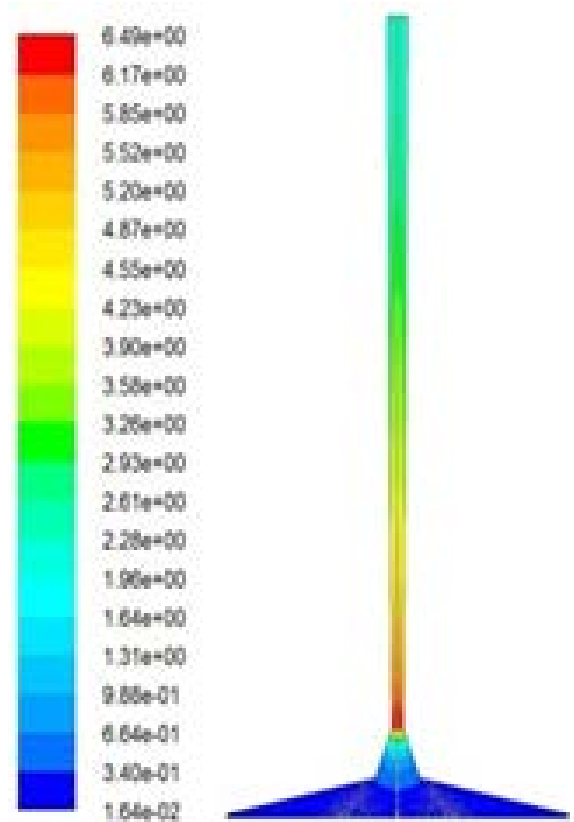

a)

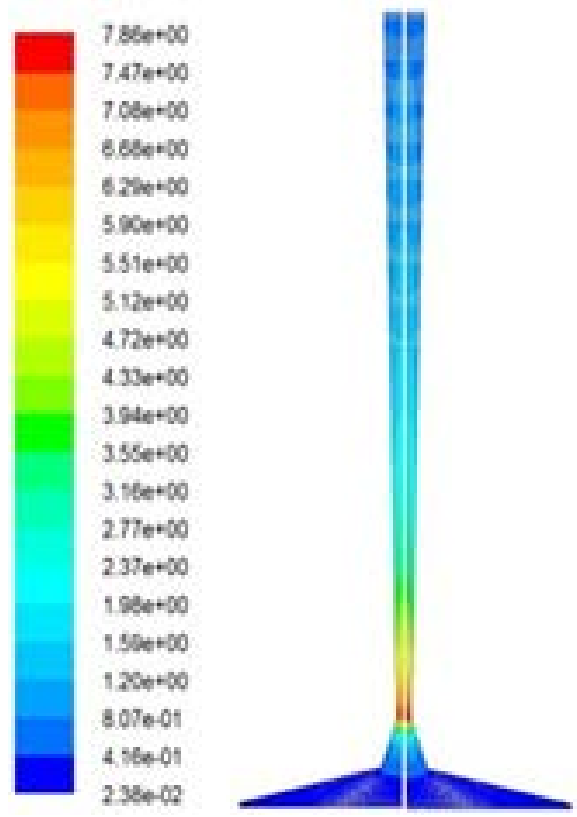

b)

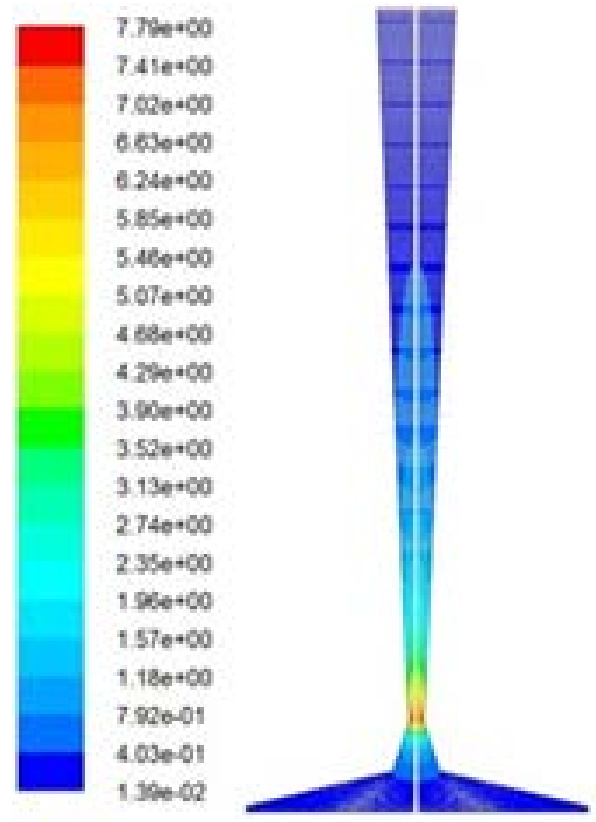

c)

Figure 6. Velocity fields attained for the best geometries obtained in Fig. 5: a) $D_{2}=0.22 \mathrm{~m}$, b) $D_{2}$ $=0.44 \mathrm{~m}$, c) $D_{2}=0.88 \mathrm{~m}$.

The results show that even simplifying the flow for an axisymmetric two-dimensional domain, it was attained results similar to those of Patel et al. (2014) for the simulation of a SCPP, especially for the prediction of the available power in the turbine region. Thereby, this model is recommended for the future studies of geometric optimization in a SCPP device.

After that, it was investigated influence of the collector inlet height $\left(H_{1}\right)$ and of the chimney outlet diameter $\left(D_{2}\right)$ over the available power of the SCPP. 
The results show that the available power $(P)$ was virtually unresponsive to the variation of parameter $H_{1}$. For example, the obtained difference between the geometries with best and worst performance, for $D_{2}$ $=0.22 \mathrm{~m}$, did not exceeded $11.0 \%$. Still, the variable $D_{2}$ did not presented great influence over the performance of the SCPP. It was also observed that there is a great value intermediate of $D_{2}\left(D_{2}=0.44\right.$ $\mathrm{m}$ ) which leads to the maximum available power of the device. In comparison with the higher and lower extremes of studied $D_{2}, D_{2}=0.22 \mathrm{~m}$ and $0.88 \mathrm{~m}$, the obtained performance was approximately $72 \%$ and $19 \%$ superior, i.e., the parameter $D_{2}$ was shown an important geometric parameter in the search for the maximization of the SCPP performance studied in the present work.

\section{ACKNOWLEDGEMENTS}

Professors J. A. Souza, L. A. O. Rocha, L. A. Isoldi and E. D. dos Santos thanks CNPq for research Grant. R. S. Vieira and C. Garcia also thank CAPES and $\mathrm{CNPq}$ for their master and undergraduate scholarships.

\section{REFERENCES}

Bejan, A., 2013, Convection Heat Transfer, Wiley, Hoboken, New Jersey, Fourth Edition.

Dhari, A., and Omri, A., 2013, A Review of Solar Chimney Power Generation Technology, International Journal of Engineering and Advanced Technology, Vol. 2, No. 3, pp. 1-17.

Ansys, 2007, Fluent Version 6.3.16, Ansys Inc.

Haaf, W., Friedrich, K., Mayr, G., and Schlaich, J., 1983, Solar Chimneys Part I: Principle and Construction of the Pilot Plant in Manzanares, International Journal of Solar Energy, Vol. 2, pp. 320.

Jones, I., 2011, Engineering Strategies for Greenhouse Gas Mitigation, Cambridge University Press, Cambridge, New York.

Launder, B. E., and Spalding, D. B., 1972, Lectures in Mathematical Models of Turbulence, Academic Press, London, England.

Li, W., Wei, P., and Zhou, X., 2014, A CostBenefit Analysis of Power Generation from Commercial Reinforced Concrete Solar Chimney Power Plant, Energy Conversion and Management, Vol. 79, pp. 104-113.

Patankar, S. V., 1980, Numerical Heat Transfer and Fluid Flow, McGraw Hill, New York, USA.

Patel, S. K., Prasad, D., and Ahmed, M. R., 2014, Computational Studies on the Effect of Geometric Parameters on the Performance of a Solar Chimney Power Plant, Energy Conversion and Management, Vol. 77, pp. 424-431.

Pretorius, J. P., and Kröger, D. G., 2006, Critical Evaluation of Solar Chimney Power Plant Performance, Solar Energy, Vol. 80, No. 5, pp. 535-
544.

Verteeg, H. K., and Malalasekera, W., 2007, An Introduction to Computational Fluid Dynamics: The Finite Volume Method, Pearson.

Wilcox, D. C., 2002, Turbulence Modeling for CFD, DCW Industries.

Xu, G., Ming, T., Pan, Y., Meng, F., and Zhou, C., 2011, Numerical Analysis on the Performance of Solar Chimney Power Plant System, Energy Conversion Management, Vol. 52, No. 2, pp. 876883.

Zhou, X., Yang, J., Xiao, B., and Hou, G., 2007, Experimental Study of Temperature Field in a Solar Chimney Power Setup, Applied Thermal Engineering, Vol. 27, No. 11-12, pp. 2044-2050. 